\title{
ALTERNATIVAS DE MANEJO PESQUEIRO NO LAGO DA USINA HIDRELÉTICA DE TUCURUÍ/PA.
}

\author{
Neila de Jesus Ribeiro Almeida ${ }^{1}$
}

\begin{abstract}
RESUMO
Esta pesquisa aborda discussões sobre o uso e acesso aos recursos pesqueiros no Lago da Usina Hidrelétrica de Tucuruí, no sudeste paraense. Busca reflexões sobre a conservação de recurso pesqueiro em Unidades de Conservação de Uso Sustentável a partir de alternativas de manejo comunitário do tucunaré - Cichla spp. A partir da ausência de um plano de manejo na reserva, pretende-se verificar alternativas de criação de um manejo comunitário a partir dos anseios da Associação dos Pescadores do Lago de Tucuruí - APLP e observar a importância do plano de manejo comunitário na reserva a partir de acordos de pesca. Desta forma, é necessário recorrer a teóricos que estudam este tema, buscando conceitos a partir das reflexões sobre o uso e acesso dos recursos que apontam para as perspectivas do co-manejo, tanto de forma mais ampla como de experiências em cenários amazônicos, onde a maioria dos estudos apontam para o manejo eficaz pautado na gestão participativa, a partir de acordos de pesca, mas principalmente utilizando-se o manejo comunitário.
\end{abstract}

Palavras-chave: Conservação. Recursos Pesqueiros. Plano de Manejo.

\begin{abstract}
This research deals with discussions about the use and access to fishing resources in the Lake of the Tucuruí Hydroelectric Power Plant, in southeastern Pará. It seeks reflections on the conservation of fishery resources in Conservation Units of Sustainable Use from alternatives of community management of tucunaré - Cichla spp. From the absence of a management plan in the reserve, we intend to verify alternatives for the creation of a community management based on the wishes of the Lago de Tucuruí Fishermen's Association - APLP and observe the importance of the community management plan in the reserve to agreements. In this way it is necessary to resort to theorists who study this theme, searching for concepts from the reflections on the use and access of resources that point to the perspectives of co-management, both in a broader way and from experiences in Amazonian scenarios, where most of studies point to effective management based on participatory management, based on fisheries agreements, but mainly using community management.
\end{abstract}

Keywords: Conservation. Fishing Resources. Management Plan.

\section{INTRODUÇÃOO}

Ao longo das últimas décadas as pressões sobre os recursos naturais vêm sendo intensificadas, mas paralelo a esse fato, as discussões sobre a gestão para a conservação desses recursos estão em evidências no Brasil e no mundo.

Essas discussões criaram destaque nacional no início dos anos 2000 com a criação do Sistema Nacional de Unidade de Conservação (SNUC), a partir da pressão para a criação da

1 Doutora em Ecologia Aquática e Pesca (PPGEAP/UFPA). Docente da Secretaria Estadual de Educação (SEDUC) e da Faculdade de Educação e Tecnologia da Amazônia (FAM). E-mail: neilalmeida2000@hotmail.com 
legislação que instituísse as áreas protegidas. Esse cenário, tem origem através de discussões sobre modelos de proteção de recursos Norte Americano, o qual vem desde o século 19 com a criação do primeiro Parque Nacional dos Estados Unidos.

Nesse contexto, o modelo desenhado no Brasil, cria além de áreas protegidas baseadas no modelo estadudinense, que trata de área intocadas, também cria um modelo de áreas em que podem ser manejadas por populações que já residem nesses espaços antes da criação das áreas protegidas.

É nesse cenário de modelos de áreas protegidas, que no Brasil são instituídas pela Lei 9.989 de 18 de Julho de 2000 (lei que cria o SNUC), que está inserida a área dessa pesquisa. A lei trata de duas categorias, uma chamada área de Uso Integral, a qual não insere atividades humanas e a outra onde exclui os chamada de área de Uso Sustentável, em que permite o acesso e uso aos recursos de forma sustentável pelas populações que residem nessas áreas.

Dessa forma, essa pesquisa a partir de levantamentos teóricos sobre a normalização dos recursos pesqueiros no país e de pesquisa de campo na área de estudo, busca percorrer sobre as formas de acesso e uso de recursos da pesca em uma Unidade de Conservação de Uso Sustentável localizada no lago da usina hidrelétrica de Tucuruí.

Nesse contexto, normalizador a legislação do SNUC, traz uma série de medidas, que podem reduzir esses conflitos e propiciar a conservação dos recursos. Entre essas medidas está o plano de manejo, que consiste em a partir de um:

Documento técnico mediante o qual, com fundamento nos objetivos gerais de uma unidade de conservação, se estabelece o seu zoneamento e as normas que devem presidir o uso da área e o manejo dos recursos naturais, inclusive a implantação das estruturas físicas necessárias à gestão da unidade. (BRASIL-SNUC, Art. $2^{\circ}$ )

Nessa perspectiva da legislação através do trabalho de campo, essa pesquisa apresenta de forma objetiva caminhos e alternativas para um plano de manejo da Reserva de Desenvolvimento Sustentável Alcobaça do lago de Tucuruí no estado do Pará.

Embora a legislação do SNUC, coloque o plano de manejo de maneira geral, abrangendo todos os recursos presentes nas unidades de conservação, geralmente o plano de manejo é feito por grupos multidisciplinares, que desenvolvem o plano de manejo por etapas, como: plano de manejo das aves, plano de manejo das espécies vegetais, plano de manejo das espécies de mamíferos, entre outros.

A partir desse desenvolvimento por etapas, essa pesquisa busca refletir sobre perspectivas para a complementação do plano manejo pesqueiro de uma espécie. Os dados 
foram levantados em 2013 e 2014 em quatro comunidades da reserva - comunidade Cametá, Água Fria, Boa Vida e Ouro Verde-, foi considerada a espécie icitiológica mais capturada nas comunidades, o tucunaré- Cichla spp.. Para os pescadores, essa espécie é considerada fundamental para a sobrevivência da população local, pois assim como serve de alimento, é a base da economia local por ter alto valor aceito no mercado com o preço do quilograma maior em relação as outras espécies capturadas.

Levando em conta a importância dos pescadores da reserva para a conservação dessas espécies, esta proposta de plano de manejo, visa o manejo comunitário, no qual nesse último, são considerados os conhecimentos e as práticas tradicionais da população local, conhecimentos esses fundamentais para a manutenção dos recursos.

\section{ASPECTOS REGULATÓRIOS DE RECURSOS PESQUEIROS}

A legislação que rege os recursos pesqueiros está subordinada a que rege a legislação agrária, isso leva coloca o direito pesqueiro a falta de autonomia e de princípios próprios que o fundamental (CAMARGO ET. AL. 2012). Nesse contexto a regularização da atividade pesqueira passa a ser feita de maneira descentralizada causando uma série de problemas de gestão e ordenamento pesqueiro.

Esse fato mostra esse cenário foi a criação da Instrução Normativa $n^{\circ} 2$ de 2011 , onde estabelece que 900 mil pescadores (em 2011) do país tiveram que se adaptar às novas regras para obter a licença e a regulamentação da profissão.

Essas ações foram tomadas pelo Ministério da Pesca e Aquicultura (MPA), no qual inseriram nessas mudanças, o cadastramento de pescadores artesanais no Registro Geral da Atividade de Pesca (RGP) e a concessão de carteira de pescador profissional. Dentre as novas medidas destacou-se a renovação da carteira de pescador, que passou a ser necessária a cada dois anos e não a cada três como definido anteriormente.

De acordo com a Política Nacional da Atividade Pesqueira, o ordenamento na pesca é o conjunto sistematizado de normas e ações que permitem administrar essas atividades, com base no conhecimento de seus componentes biológicos-pesqueiros, ecossistêmicos, econômicos e sociais (CAMARGO ET. AL., 2012).

Porém se o ordenamento da pesca visa sistematizar normas e ações com base em componentes sociais, o que se pode entender é que cada vez a gestão da pesca se distancia mais do pescador, impondo regras que dificilmente será cumprida.

Nesse contexto, o processo de regularização que vem ocorrendo no setor pesqueiro está deixando os pescadores preocupados com tanta burocracia para obtenção do Registro 
Geral na Atividade Pesqueira. Se por um lado o antigo Ministério da Pesca e Aquicultura alegava que o processo de regularização dos pescadores faz parte de um sistema de proteção ao recurso pesqueiro, pois a fiscalização é difícil, e o orçamento do ministério e das secretarias não é grande.

Por outro lado, existem diversos estudos, principalmente na Amazônia, que mostram a gestão participativa a partir de acordos de pesca, onde os pescadores fazem parte da tomada de decisão juntamente com órgãoslinstituições e são os próprios fiscais dos recursos pesqueiros.

Outro fato levantado por Camargo et. al. (2012) que mostra a incoerência na gestão pesqueira é que a fiscalização das atividades de pesca e aquicultura estava sendo de competência do antigo Ministério da Pesca e Aquicultura (MPA).

Contudo, no âmbito de suas competências, esse ministério não exercia poder de "polícia ambiental", esse poder é de competência do Instituto Brasileiro do Meio Ambiente e dos Recursos Naturais Renováveis (IBAMA). Em quanto que em área de unidades de conservação instituídas pela União, quem passava a ter poder de "polícia suplementar" é o Instituto Chico Mendes de Conservação e Biodiversidade (ICMBio).

Este situação, mostra três órgãos federais, com o mesmo poder, gerando assim conflitos na própria esfera que deveria organizar o setor pesqueiro.

Esse processo pode ser observado na Unidade de Conservação - Reserva de Desenvolvimento Sustentável Alcobaça no lago de Tucuruí em esfera estadual e federal. A UC foi criada pela Secretaria Estadual de Meio Ambiente (SEMA), mas o IBAMA e a ELETRONORTE tem poder de fiscalização, assim como a SEMA também é responsável pela fiscalização, bem como ICMBio poderia também fiscalizar por ser uma Unidade de Conservação.

Porém no meio de toda essa gestão sobreposta, estão os os pescadores que vivem diretamente da captura das espécies e que deveria ser o principal responsável pela fiscalização dos recursos quando considerada uma gestão compartilhada.

Nesse sentido, considerando que a pesca, em especial na região Amazônia, é considerada uma das atividades mais importantes, pois é base da alimentação da população local, especialmente das comunidades que vivem nas margens dos rios, essa atividade também gera renda para a população local e favorece o comércio local (ISAAC ET. AL., 1996; SANTOS e SANTOS, 2005). 


\section{ALTERNATIVAS DE MANEJO COMUNitÁRIO}

Estudos realizados por Hardin (1968) apontam a ideia que para ser evitada uma tragédia da escassez dos recursos naturais, seria que esses recursos deveriam ser regularizados pelo Estado ou por inciativas privados, através de regras e normas para o acessos e uso desses recursos.

Ao longo do tempo essa idéia vem sendo discutida e estão sendo inseridas alternativas que regulamentam o acesso e uso dos recursos. Estudos mostram que todas as formas de manejo: estatal privado, de livre acesso e comunitário, se não forem bem elaborados, e não levarem em consideração as especificidades locais de cada cenário, fortalecendo a gestão participativa com rigor, todas as formas, tendem ao fracasso (FEENY ET. AL., 2001; OVIEDO, 2003; CUNHA, 2004).

Nesse contexto, outras pesquisas vêm sendo desenvolvidas e apontando que das quatro formas de manejo realizadas, o manejo comunitário pode ser realizado com sucesso. Experiências na Amazônia apontam o manejo pesqueiro eficaz pautado na gestão participativa, a partir de acordos de pesca, e do co-manejo (McGRATH ET.AL., 1998; BENATTI ET. AL., 2003; ALMEIDA, 2006; KALIKOSKI ET.AL.,2009; CASTRO ET.AL., 2011; SEIXAS ET. AL., 2011).

As políticas públicas do setor pesqueiro vem tomando medidas "administrativaslegislação" para "apoiar" o plano de manejo a partir de acordos de pesca com gestão participativa. Um dos fatos que apontam para esse fim, é que em 2002 foi criada pelo Instituto Brasileiro do Meio Ambiente e dos Recursos Naturais Renováveis (IBAMA) a Instrução Normativa que estabelece critérios e procedimentos para regularização de Acordos de Pesca em comunidades pesqueiras e para complementar.

Nesse sentido, apoiando essa ideia, em 2007 o Ministério do Meio Ambiente (MMA) através do Instituto Chico Mendes de Conservação da Biodiversidade (ICMBio), criou a Instrução Normativa que disciplina as diretrizes, normas e procedimentos para a elaboração de Plano de Manejo Participativo de Unidade de Conservação Federal das categorias Reserva Extrativista (RESEX) e Reserva de Desenvolvimento Sustentável (RDS), embora a instrução seja de cunho federal, as Unidades de Conservação estaduais podem adequar a Instrução Normativa a realidade local. De acordo com a Instrução Normativa $n^{\circ} 01$, de 18 de setembro de 2007, entende-se por Plano de Manejo Participativo de RESEX ou RDS:

Documento que representa o principal instrumento de gestão da Unidade de Conservação, definindo sua estrutura física e de administração, o 
zoneamento, as normas de uso da área e de manejo dos recursos naturais e os programas de sustentabilidade ambiental e sócio-econômica, construído junto com a população tradicional da Unidade (BRASIL- Instrução Normativa \MMA-ICMBio, $\left.\mathrm{n}^{\circ} 01,2007\right)$.

Essas políticas desenhadas pelo Estado, como a Instrução Normativa citada anteriormente, são processos que deveriam dá certos se recebessem do próprio Estado incentivos para colocar em prática as ações previstas na legislação. Porém, considerando a realidade, trata-se de uma lei com muitas dificuldades de ser cumprida, pela falta de incentivos de políticas públicas para a conservação dos recursos.

Estudos realizados por Benatti et. al. (2003) apontam experiências de manejo comunitário na Amazônia a partir de acordos de pesca que deram certo. $\mathrm{O}$ autor destaca que quando todos os segmentos sociais estão envolvidos, as experiências de manejos comunitários são bem sucedidos, mas chama atenção que esse sucesso se deu pela organização de todos os segmentos sociais, inclusive a igreja.

O manejo comunitário na reserva Alcobaça é possível, se forem levadas em conta todos os segmentos que regem o uso e acesso de recursos. Nesse contexto, destaca-se o manejo comunitário do tucunaré- Cichla spp., pois essa espécie é considerada uma das mais importantes para a população da reserva, pois é utilizada tanto para o consumo dos pescadores como para a comercialização.

De acordo com pesquisas realizadas por Camargo e Petrere (2004) esta espécie é uma dos topos de comercialização nos portos da região. Levando em consideração a importância dessa espécie, a captura é feita de forma intensa, Alves e Barthem (2008) verificaram que a pesca do tucunaré, além de ser realizada com anzol, também é utilizado o arpão, considerado apetrecho ilegal pela legislação. Isso preocupa os pescadores locais, pois na pesca com arpão o único critério utilizado para a captura do tucunaré é o tamanho do pescado, e este critério não considera o sexo do pescado e tão pouco o período de reprodução.

Levando em conta esse tipo de pesca, os conflitos são presentes entre os pescadores da reserva, pois uns respeitam e só pescam com anzol e outros utilizam o arpão na pesca de mergulho. Por outro lado, existem pescadores que entram na reserva para pescar com arpão e zagaia, vindos de outras áreas do lago e até mesmo de outras regiões do estado, causando maiores conflitos.

Essas atividades que desencadeiam em conflitos, apontam para a sobre-pesca do tucunaré e consequentemente a escassez dessa espécie. Isso torna-se grande preocupação para os pescadores, pois esta espécie é muito importante para a sobrevivência de todos. 
Estes fatos levam os pescadores se reunirem e discutirem o manejo do tucunaré nas reuniões do Conselho Deliberativo da reserva Alcobaça, esse conselho é formado pelos seguintes representantes: Centrais Elétricas do Norte do Brasil S.A. (ELETRONORTE), Secretaria Estadual de Meio Ambiente - Área de Proteção Ambiental (SEMA-APA), Secretaria Estadual de Meio Ambiente - Reserva de Desenvolvimento Sustentável (SEMARDS), Colônia de Pescadores, Prefeitura Municipal de Tucurú e Pescadores da Reserva.

Assim, as discussões sobre o plano de manejo, já vem ocorrendo algum tempo, porém as aplicações ainda estão muito distantes, não há organização quanto as práticas das atividades pesqueiras, e os órgãos do Governo, falam em plano de manejo, mas sempre deixando claro as dificuldades de implementação, e o manejo comunitário fora das discussões.

\section{A ÁREA DE ESTUDO}

\subsection{A REGIÃO}

A Reserva de Desenvolvimento Sustentável Alcobaça (tracejo em amarelo), localizase nos municípios de Tucururí e Novo Repartimento, no estado do Pará. Foi criada pela Secretaria Estadual de Meio Ambiente, Lei Estadual No 6.451 de 08 de Abril de 2002, objetivando servir como instrumento de conservação da biodiversidade degradada pelas obras realizadas com a construção da Usina Hidrelétrica de Tucuruí-UHT, e para atenuar os múltiplos conflitos territoriais locais, decorrentes da implantação deste empreendimento (ARAÚJO; ROCHA, 2008).

A reserva Alcobaça recebeu esse nome em homenagem a antiga vila de Alcobaça que recebeu projetos ali instalados e inconclusos, tais como a estrada de ferro e a construção da hidrelétrica do Tucuruí. O nome dado a região antes da criação da reserva, era região do Caraipé, sendo que até hoje, os moradores mais antigos denominam a região de Caraipé e não de Alcobaça.

Segundo o SNUC em seu artigo $20^{\circ}$ destaca que uma Reserva de Desenvolvimento Sustentável (RDS), unidade de conservação de uso sustentável, se caracteriza por ser uma área natural que abriga populações tradicionais, cuja existência baseia-se em sistemas sustentáveis de exploração dos recursos naturais, desenvolvidos ao longo de gerações e adaptados às condições ecológicas locais e que desempenham um papel fundamental na proteção da natureza e na manutenção da diversidade biológica. 
As reservas de desenvolvimento sustentável têm como principal objetivo preservar a natureza e, ao mesmo tempo, assegurar as condições e os meios necessários para a reprodução e a melhoria dos modos e da qualidade de vida e exploração dos recursos naturais das populações tradicionais, bem como valorizar, conservar e aperfeiçoar o conhecimento e as técnicas de manejo do ambiente, desenvolvido por estas populações (BRASIL-SNUC, 2000).

\subsection{O AMBIENTE}

O ambiente da Reserva de Desenvolvimento Sustentável Alcobaça segundo Ribeiro et. al. (1995), pertence à bacia do rio Tocantins-Araguaia, esta bacia apresenta uma grande área de captação, que se estende de 460 a 550 oeste e 2 o a 18 o Sul, drenando uma área de $767.000 \mathrm{~km} 2$, dos quais $343.000 \mathrm{~km} 2$ correspondem ao rio Tocantins, $382.000 \mathrm{~km} 2$ ao rio Araguaia (seu principal afluente) e $42.000 \mathrm{~km} 2$ ao rio Itacaiúnas.

A configuração do Tocantins- Araguaia é no sentido latitudinal alongada, abrangendo áreas dos Estados de Goiás, Mato Grosso, Pará, Maranhão e Distrito Federal e ainda fazendo limites com as bacias do Paraná, Paraguai, Xingu, São Francisco e Parnaíba. Várias conexões existem ou são supostas ao nível das cabeceiras e que possibilitam a dispersão dos peixes, aumentando, assim, a área de distribuição de algumas espécies. No Pará na região de Tucuruí as altitudes são inferiores a 100 metros (RIBEIRO ET AL., 1995; MÉRONA ET AL, 2010).

Essas particularidades a bacia Araguaia-Tocantins, apresenta uma vasta biodiversidade ictiológica. O trecho do baixo Rio Tocantins, onde se localiza a usina hidrelétrica de TucuruíUHT, de acordo com Mérona et. al (2010) a região era geomorfologicamente, antes da formação do lago, uma região propícia a diversidade e abundância da icitiofauna, configurando uma relação forte de pesca na região.

A reserva Alcobaça está localizada no grande lago. O lago de Tucuruí tem cerca de $100 \mathrm{~km}$ de extensão, por $18 \mathrm{~km}$ de largura e tem um meandro de cerca de 1500 ilhas que compõem um cenário amplo e diversificado, tanto no que se refere ao ecossistema que findou por se criar no decorrer de sua formação, como pela variedade de atores sociais resultantes de um processo de formação local, mas oriundo também de movimentos migratórios avançando sobre áreas de fronteira, como a Amazônia. (JATOBÁ, 2006).

\section{A PESCA: IMPORTÂNCIA, CONFLITOS E ESCASSEZ DE RECURSOS.}

Trinta anos depois da construção da barragem de Tucuruí, a pesca no lago de Tucuruí, ainda é considerada intensa. De acordo com Cintra et al. (2007) os peixes da região do reservatório de Tucuruí, são de extrema importância econômica e social para os municípios 
que estão a montante e a jusante, mas especialmente para os pescadores que residem no lago e que vivem diretamente da ictiofauna.

Segundo estudos realizados por Camargo e Petrere (2004) até o início dos anos 90, cerca de 6.000 pescadores atuavam no reservatório, movimentando R $\$ 4,2$ milhões por ano. Estes números, de acordo com estimativas dos presidentes das colônias de pescadores do entorno do reservatório, permanecem atuais. Os pescadores locais atuam com artes de rede e anzol, e suas principais espécies-alvo são o mapará, (Hypophthalmus marginatus, Valenciennes, 1840), capturado apenas com rede; o tucunaré (Cichla spp.), capturado predominantemente com anzol, e a pescada (Plagioscion squamosissimus, Heckel, 1840), capturada com rede ou anzol.

A vegetação submersa, provocada pela formação do lago estimulou uma alta produtividade primária no reservatório, isso ocasionou um estoque crescente de recursos pesqueiros, inclusive do filtrador Hypophthalmus marginatus que, atualmente, é uma das principais espécies comerciais da região. Porém esta situação de aparente calma e estabilidade de estoque não deixou de despertar o interesse dos órgãos ambientais governamentais e instituições não-governamentais, relacionados ao setor pesqueiro.

O crescimento da economia local, impulsionado pela construção da barragem e facilidade de acesso, tem provocado um aumento na pressão sobre os recursos naturais, exigindo o imediato planejamento daquilo que se pretende realizar a médio e longo prazo (CAMARGO; PETRERE, 2004).

Desta forma o tucunaré - Cichla spp. (Figura 1) como já mencionado, é uma das espécies mais importante para a população de pescadores da reserva, pois é base do consumo local e fonte de renda pelo seu fácil aceite no mercado, este fato chama atenção para o manejo.

Figura 1 - Tucunaré - Cichla spp.

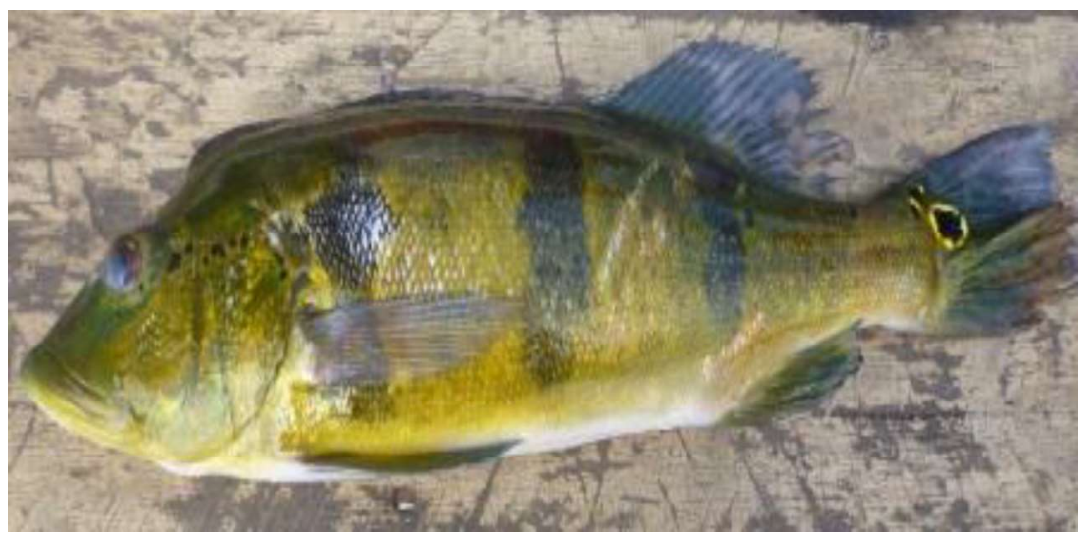

Fonte: Almeida, 2013. 


\section{PERSPECTIVAS PARA O MANEJO DA ESPÉCIE Cichla spp.}

\subsection{ACORDOS DE PESCA}

A proposta de acordo de pesca na área desse estudo, pode ser válida para o manejo comunitário, Almeida (2006) pesquisou este tipo de manejo com pescadores de pequena escala no Baixo Amazonas, e mostrou que esta proposta se desenvolvida obedecendo todas as regras, pode ocasionar a conservação dos recursos pesqueiros. A Instrução Normativa do IBAMA, traz o acordo de pesca como sendo:

Um conjunto de medidas específicas decorrentes de tratados consensuais entre os diversos usuários e o órgão gestor dos recursos pesqueiros em uma determinada área, definida geograficamente (BRASIL- Instrução Normativa n²9\BAMA, 2002).

Esses acordos podem ser propostos para o manejo na reserva Alcobaça, pois a partir da identificação dos problemas existente, como os tipos de técnicas e apetrechos utilizados que prejudicam a estabilidade ao tucunaré- Cichla spp., o manejo comunitário se aplicaria nas comunidades da reserva.

Esse manejo, implicaria diretamente na espécie estudada, a partir da organizada dos pescadores com o cumprimento das normas e regras em períodos proibidos para captura.

Nesse sentido, para este tipo de acordo, as comunidades deveriam organizar-se através dos líderes comunitários e levariam para as reuniões do conselho da Alcobaça (órgãos governamentais e não governamentais, colônia de pescadores e comunidade da reserva em geral) as propostas dos acordos de pesca, onde os próprios pescadores poderiam fazer a fiscalização com bases, impedindo o acesso de pescadores externos nos rios da reserva em período de reprodução da espécie e entre os pescadores da reserva seria regulado o tipo de apetrecho utilizado na captura da espécie.

Levando em conta estudos de McGrath (1998) no modelo de manejo comunitário, pescadores das comunidades controla o acesso e o uso de um território pesqueiro bem definido. No caso dos pescadores Alcobaça o território de pesca está bem definido, é o próprio território da reserva, já regulamentado o uso e acesso na criação desta unidade de conservação. Os pescadores locais só tem que regulamentar as regras de uso com a participação da SEMA, ELETRONORTE, Colônia de Pescadores e outras instituições envolvidas na gestão da reserva, pois a fiscalização é uma responsabilidade da comunidade que recebe o apoio dos outros órgãos. 


\subsection{APOIO NO PERÍODO DE SECA NO LAGO}

Tratando da sazonalidade da área de estudo, o período em que o lago se encontra com a água baixa, chamado aqui de seca, e com a água elevada chamado aqui nesse trabalho de cheia, vai muito além de período chuvoso ou não chuvoso na Amazônia.

Embora tenha sido identificado que os pescadores da Alcobaça compreendem que essa dinâmica das águas, acontece pela pluviosidade amazônica, foi constatado que o nível das águas também está diretamente relacionado com o funcionamento da usina, diretamente ligado a produção de energia elétrica.

Nesse sentido, vale ressaltar que independente das causas que dinamizam o nível da água, as dificuldade no período de seca são muito mais evidentes para população. A partir dessa lógica, o Estado poderia criar programas elou projetos com alternativas de sobrevivência para estes pescadores nessa época. Uma das alternativas seria o apoio no transporte para a captura e comercialização do tucunaré, já que as embarcações utilizadas no período de cheia ficam restritas aos níveis dos rios no período de seca do lago.

Outra alternativa seria criar meios de outros tipos de produção para a redução de captura do tucunaré, dando assim o tempo necessário para o crescimento da espécies, já que no período de seca, a forma mais prática de captura desta espécie é o arpão e a zagaia, modelos considerados ilegais e invasivos a conservação da espécie.

Como as unidades de conservação de uso sustentável já trazem em seu objetivo um discurso de apoio as populações locais para a conservação dos recursos naturais, esta proposta serviria de apoio as populações nessa época em que tudo está mais difícil para as comunidades. Nesse caso a SEMA e a ELETRONORTE seriam as principais frentes de acordos com a população, servindo para o manejo e conservação do tucunaré através de apoio e alternativas de outras atividades.

\subsection{GESTÃO COMPARTILHADA: METAS PARA O MANEJO DO CICHLA SPP.}

Considerando a proposta de gestão compartilhada, alguns estudos desenvolvidos mostram que esse tipo de gestão está ligada diretamente na eficácia do manejo comunitário (SEIXAS ET. AL., 2011; KALIKOSKI ET AL., 2009; BENATTI ET. AL., 2003; OSTROM, 2002). Assim a proposta de manejo do tucunaré- Cichla spp. na reserva de desenvolvimento sustentável Alcobaça no lago de Tucuruí, orienta-se que a comunidade de pescadores, em parceria com os órgãos e instituições governamentais que estão envolvidas na gestão da Alcobaça, desenvolvam em conjunto as normas, as regras e as devidas estruturas que a legislação traz, para a gestão participativa dos recursos pesqueiros da região, a partir dos 
acordos de pesca da espécie Cichla spp.. A Instrução Normativa n 29, de 2002 do IBAMA, trás em seus anexos procedimentos para se estabelecer acordos de pesca (Quadro 01).

Quadro 01- Estabelecimento para acordos de pesca

\section{PROCEDIMENTO PARA ESTABELECIMENTO DE ACORDOS DE PESCA}

\begin{tabular}{|c|c|}
\hline 1- MOBILIZAÇÃO & $\begin{array}{l}\text { ·Planejar as reuniões comunitárias; } \\
\text { ·Encaminhar convite oficial a todos os segmentos, } \\
\text { relacionados com a atividade pesqueira,com pauta, dia, } \\
\text { local e horário, com ciência (folha com assinatura); } \\
\text { · Realizar reunião com lideranças comunitárias, } \\
\text { representantes de Colônia de Pescadores, Órgão Estadual } \\
\text { de Meio Ambiente. }\end{array}$ \\
\hline $\begin{array}{l}\text { 2-REUNIÕES } \\
\text { COMUNITÁRIAS }\end{array}$ & $\begin{array}{l}\text {. Apresentar o problema; } \\
\text {-Discutir as diferentes idéias e propostas } \\
\text { considerando a legislação vigente, na busca da construção } \\
\text { do consenso; } \\
\text {-Eleger representantes das comunidades para } \\
\text { encaminhar, discutir e defender suas propostas na } \\
\text { Assembléia Intercomunitária; } \\
\text {.Convidar, para acompanhamento técnico, } \\
\text { representantes do IBAMA e outras instituições parceiras. }\end{array}$ \\
\hline $\begin{array}{l}\text { 3-ASSEMBLEIAS } \\
\text { INTERCOMUNITÁRIAS }\end{array}$ & $\begin{array}{l}\text { ·Convidar os representantes de todas as } \\
\text { comunidades envolvidas no Acordo, assim como os demais } \\
\text { usuários e/ou grupos de interesse nos recursos naturais da } \\
\text { área a ser manejada, tais como: Colônia de Pescadores } \\
\text { local, associações, organizações ambientalistas, sindicatos; } \\
\text { ·Apresentar as diferentes propostas existentes; } \\
\text { Sistematizar e Aperfeiçoar as propostas; } \\
\text { Convidar, para acompanhamento técnico, } \\
\text { representantes do órgão ambiental competente e outras } \\
\text { instituições parceiras. }\end{array}$ \\
\hline $\begin{array}{l}\text { 4- RETORNO DAS } \\
\text { PROPOSTAS PARA AS } \\
\text { COMUNIDADES }\end{array}$ & $\begin{array}{l}\text { Cada representante volta à sua comunidade } \mathrm{e} \\
\text { apresenta e esclarece as propostas pré-aprovadas durante a } \\
\text { Assembléia Intercomunitária; } \\
\text {-Se pertinente, as comunidades podem encaminhar } \\
\text { novas sugestões. }\end{array}$ \\
\hline $\begin{array}{c}\text { 5- ASSEMBLEIAS } \\
\text { INTERCOMUNITÁRIAS }\end{array}$ & $\begin{array}{l}\text { ·Devem ser realizadas quantas Assembléias se } \\
\text { fizerem necessárias até se obter um consenso das propostas } \\
\text { entre os diferentes usuários da área a ser manejada. }\end{array}$ \\
\hline $\begin{array}{l}\text { 6-ENCAMINHAMENTO AO } \\
\text { ÓRGÃO COMPETENTE }\end{array}$ & $\begin{array}{l}\text { ·A proposta de Acordo de Pesca acompanhado da } \\
\text { Ata da Assembléia que o aprovou, contendo as assinaturas } \\
\text { de todos os representantes das comunidades e demais } \\
\text { participantes, deve ser encaminhada ao órgão competente, } \\
\text { através de Ofício, solicitando sua regulamentação através } \\
\text { de Portaria Normativa Complementar. } \\
\text { OO órgão de posse da documentação elaborará } \\
\text { minuta de Portaria regulamentando o referido Acordo e } \\
\text { encaminhará para apreciação técnica e jurídica, e demais } \\
\text { providências cabíveis. }\end{array}$ \\
\hline & Uma vez a Portaria publicada no Diário Oficial da \\
\hline
\end{tabular}




\begin{tabular}{|c|c|}
\hline $\begin{array}{l}\text { 7- DIVULGAÇÃO DA } \\
\text { PORTARIA }\end{array}$ & $\begin{array}{l}\text { União, recomenda-se distribuir cópias a todas as } \\
\text { comunidades e instituições que participaram das discussões } \\
\text { referidas. } \\
\text { ·Ainda, se possível, divulgar a Portaria pelos meios } \\
\text { de comunicação disponíveis. }\end{array}$ \\
\hline 8- MONITORAMENTO & $\begin{array}{l}\text { O monitoramento do Acordo de Pesca deve ser } \\
\text { estabelecido com base em métodos e indicadores possíveis } \\
\text { de serem cumpridos. } \\
\text { - Recomenda-se que o plano de monitoramento } \\
\text { estabelecido seja acompanhado de técnico de órgão } \\
\text { ambiental, preferencialmente IBAMA, OEMAs, ONGs. }\end{array}$ \\
\hline 9- AVALIAÇÃO & $\begin{array}{l}\text { Com base nas informações disponibilizadas pelo } \\
\text { monitoramento, deverão ser realizadas avaliações anuais } \\
\text { do Acordo de Pesca para análise dos resultados e } \\
\text { alterações que se fizerem necessárias. }\end{array}$ \\
\hline
\end{tabular}

Fonte: Adaptado do anexo I da Instrução Normativa nº20 de 2002 do IBAMA.

Para um manejo comunitário do Cichla spp. na reserva Alcobaça, os órgãos linstituições e pescadores locais, precisam implantar (Quadro 02):

Quadro 02- Expectativas para o manejo a partir de acordos de pesca na RDS Alcobaça.

\section{CENÁRIOS ESPERADOS PARA 5 A 10 ANOS TENDO CUMPRIDO OS ACORDOS PARA O MANEJO COMUNITÁRIO DA RDS ALCOBAÇA-TUCURUÍ/PA}

- Criação Conselhos de Pesca. Os Conselhos são compostos de representantes de todas as comunidades localizadas na reserva Alcobaça, já que em todas as comunidades da reserva residem pescadores.

- Os Conselhos se reúnem mensalmente e são responsáveis pela elaboração e implementação dos acordos de pesca. Os acordos de pesca são acordos intercomunitários que definem as regras para a pesca nos rios da reserva, tais como: área a ser manejada, tipos de técnicas e apetrechos a seres utilizadas na captura do Cichla spp., os pescadores externos da reserva só podem pescar a espécie manejada com anzol e em pequenas embarcações fora dos períodos de reprodução, nessa época os pescadores que residem na Alcobaça podem pescar, mas existe uma quantidade equivalente para cada família, sendo que em todo o ano só será permitida a pesca com anzol, inclusive no período de seca dos rios da reserva.

- Já houve as escolhas dos agentes ambientais voluntários para organizar a físcalização dos rios da reserva, com o apoio dos fiscais da SEMA, esses agentes são credenciados por órgãos competentes que dão autonomia para essa fiscalização. Para esta fiscalização e monitoramento os pescadores receberam capacitação dos órgãos competentes.

- Nos torneios de pesca esportiva, além da SEMA os pescadores fazem a fiscalização, o tucunaré que por algum motivo não poder retornar ao seu habitat natural será doado para os pescadores da reserva.

- Há uma cobrança de taxa sobre a captura de peixes na Alcobaça, a fim de gerar fundos para custear as atividades dos Conselhos e dos agentes ambientais. Por exemplo, R\$ 0,50 a cada quilograma de Cichla spp. capturado e comercializado.

- No período de seca os pescadores tem apoio da ELETRONORTE para a agricultura (mandioca, milho...) e até mesmo na pesca para escoar a produção.

- Os pescadores têm auxílio para armazenar e comercializar a espécie sem perder a produção por falta de gelo, por exemplo. Em um cenário de coletividade. 
- O envolvido no acordo que descumprir as regras será proibido de comercializar o pescado capturado, podendo realizar a pesca apenas para consumo próprio.

Fonte: Diagnóstico bibliográfico e de campo.

\section{REFERÊNCIAS}

ALMEIDA, O. T. de. Manejo de Pesca na Amazônia Brasileira. São Paulo: Peirópolis, 2006.

ALVES, M. C. B.; BARTHEM, R. B.. A pesca comercial dos "tucunarés" Cichla spp. (Perciformes, Cichlidae) no reservatório da UHE-Tucuruí, rio Tocantins, PA. Boletim do Instituto de Pesca, São Paulo, v.34, n.4, p.553-561, 2008.

ARAÚJO,A. R.; ROCHA, G. M. Unidades de Conservação em Tucuruí/PA como instrumento de Gestão Territorial. In: IV Encontro Nacional da Anppas. Brasília-DF. 2008.

BENATTI, J. H.; MCGRATH, D. G.; OLIVEIRA, A. C. M. de. Políticas públicas e manejo comunitário de recursos naturais na Amazônia. Ambient. soc., Campinas, v. 6, n. 2, Dec. 2003.

BRASIL . Lei $n^{\circ}$ 9.985, de 18 de julho de 2000; Decreto $n^{\circ} 4.340$, de 22 de agosto de 2002. Sistema Nacional de Unidade de Conservação da Natureza - SNUC: 3. ed. aum. Brasília: MMA/SBF, 2003.52p.

BRASIL. Instrução Normativa $\mathrm{n}^{\circ}$ 02, de 25 de janeiro de 2011. Dispõe sobre os procedimentos administrativos para a inscrição de pessoas físicas no Registro Geral da Atividade Pesqueira nas categorias de Pescador Profissional e de Aprendiz de Pesca no $\begin{array}{llllll}\text { âmbito do } & \text { MPA. } & \text { Disponível } & \text { em: }\end{array}$ $\underline{\text { sinpesq.mpa.gov.br/.../instrucao normativa } 02 \text { 26jan11 retificada } \% 20}<$ Acesso: 05 fev.2014.

Instrução Normativa $n^{\circ} 29$, de 31 de dezembro de 2002. Estabelece critérios e procedimentos para regularização de Acordos de Pesca em comunidades pesqueiras. Disponível em: http://www.ibama.gov.br/documentos-recursos-pesqueiros/instrucaonormativa/ Acesso: 05 fev.2014.

. Instrução Normativa $\mathrm{n}^{\circ}$ 01, de 18 de setembro de 2007. Disciplina as diretrizes, normas e procedimentos para a elaboração de Plano de Manejo Participativo de Unidade de Conservação Federal das categorias Reserva Extrativista e Reserva de Desenvolvimento Sustentável. Disponível em: > http://www.icmbio.gov.br/portal/quemsomos/legislacao/instrucoes-normativas.html< Acesso: 22 jan.2014.

CAMARGO, S. A. F. de.; SOUZA, A.S.; CAMARGO, T.R.L. O direito pesqueiro no ordenamento jurídico brasileiro. In. CAMARGO, S.A.F. \& CAMARGO, T.R.L.(orgs). Direito, política e manejo pesqueiro na Bacia Amazônica. São Carlos: RiMA editora, 2012.

CAMARGO, S. A. F. de; PETRERE JR, M. Análise de risco aplicada ao manejo precaucionário das pescarias artesanais na região do reservatório da UHE-Tucuruí (Pará, Brasil). Acta Amazônica, Manaus, 2004. 
CASTRO, F. de; HOGENBOOM, B.; BAUD, M. Governança ambiental na América Latina: para uma agenda de pesquisa mais integrada. Ambient. soc., São Paulo, v. 14, n. 2, dez. 2011.

CINTRA, I. H.; JURAS, A. A.; ANDRADE, J. A.; OGAWA, M. Caracterização dos embarques pesqueiros na área de influência da usina hidrelétrica de Tucuruí, estado do Pará, Brasil. Boletim Técnico-Científico do CEPNOR, v. 7, p. 135-152, 2007.

FEENY, D. BERKES, F. McCAY, B. ACHESON, J.. A Tragédia dos Comuns Vinte e Dois Anos Depois. Páginas 17 a 42. In DIEGUES, A.C. e MOREIRA, A.C. (Orgs). Espaços e Recursos Naturais de Uso Comum. NUPAUB-USP, São Paulo.

HARDIN, G. The tragedy of the Commons. Science, V. 162, n. 3859, p. 1243-1248. 1968.

JATOBÁ, S. U. S. Gestão do Território e a produção da socionatureza nas Ilhas do Lago de Tucuruí na Amazônia Brasileira. Tese apresentada ao Centro de Desenvolvimento Sustentável da Universidade de Brasília, 2006.

KALIKOSKI, Daniela Coswig; SEIXAS, Cristiana Simão; ALMUDI, Tiago. Gestão compartilhada e comunitária da pesca no Brasil: avanços e desafios. Ambient. soc., Campinas, v. 12, n. 1, jun. 2009.

MAgAlHÃES, S. B. Política e sociedade na construção de efeitos das grandes barragens: o caso Tucuruí. In: Tenotã- Mõ: Alertas sobre conseqüências dos projetos hidrelétricos no rio Xingu. Organizador: A. Oswaldo Sevá Filho. 344p. Editora IRN, 2005.

MÉRONA, B. de. Ecologia da pesca e manejo pesqueiro na região amazônica. Bol. Mirs: Para. Endio Goeldi, ser. Antropal. Il(?), 1995.

MÉRONA, B. de; JURAS, A. A.; SANTOS, G. M. dos; CINTRA, I. H. Os peixes e a pesca no baixo Rio Tocantins: vinte anos depois da UHE Tucuruí. Centrais Elétricas do Norte do Brasil S.A - Eletrobrás Eletronorte. Brasília, 2010.

McGRATH, D.; CASTRO, F.; CÂMARA, E.; FUTEMMA, C. Manejo Comunitário de Lagos de Várzea e o Desenvolvimento Sustentável da Pesca na Amazônia. Novos Cadernos NAEA, Vol 1 (2),1. p. 5-34. 1998.

OSTROM, E. Reformulando los bienes comunes. In SMITH, Richard Chase \& PINEDO, Danny. El cuidado de los bienes comunes: gobierno y manejo de los lagos y bosques en la Amazonía. Lima-Peru: IEP, Instituto del Bién Comun, 2002.

RIBEIRO, M. C. L. B., PETRERE - JUNIOR, M., Juras, Anastácio Afonso. Ecological integrity and fisheries ecology of the Araguaia - Tocantins river basin, Brazil. Regulated Rivers: Research \& Management, 11: 325 - 350, 1995.

SANTOS, G. M. dos; SANTOS, A. C. M. dos. Sustentabilidade da pesca na Amazônia. Estudos Avançados, São Paulo, 2005.

SEIXAS, C. S. KALIKOSKI, D.; ALMUDI, T.; BATISTA, V.; COSTA, A.; DIOGO, H.; FERREIRA, B.; FUTEMMA, C.; MOURA, R.; RUFFINO, M.; SALLES, R.;THÉ, A. 
Gestão compartilhada do uso de recursos pesqueiros no Brasil: elementos para um programa nacional. Ambient. soc., São Paulo, v. 14, n. 1, jun. 2011.

Recebido em 17.03.2019

Aprovado em 24.03.2019 